\title{
Comunicación

\section{Comunicación pública, transición política y periodismo en México: el caso de Aguascalientes}

SALVADOR DE LEÓN 1

A través de la relación entre periodistas, propietarios de medios, políticos y relacionistas de las fuentes políticas, en el texto se analiza la comunicación pública en Aguascalientes. Los hallazgos se vinculan con las transformaciones políticas y la apertura económica ocurridas en México desde la década de 1990. La discusión refiere el modo en el que se configura la comunicación pública en sociedades en transición, como la mexicana.

PALABRAS CLAVE: Comunicación pública, periodismo político, sociedades en transición, investigación cualitativa.
This intervention provides an analysis of public communication in the city of Aguascalientes. Findings are linked to political changes and processes of economic liberalization that took place in Mexico during the 1990s. The argument is then made that societal transitions in developing countries are characterized by dynamics of deliberative democracy which configure processes of public communication.

KEY WORDS: Public communication, political journalism, transition societies, qualitative research.

1 Universidad Autonóma de Aguascalientes, México.

Correo electrónico: sdeleon@correo.uaa.mx 


\section{CAMBIO POLÍTICO-ECONÓMICO \\ Y COMUNICACIÓN PÚBLICA EN MÉXICO}

Es evidente que las condiciones políticas y económicas que hoy tenemos en México son distintas a las que existieron durante la mayor parte del siglo XX. En la década de 1990 se consolidó un modelo de apertura económica que ha dejado atrás la industrialización y la sustitución de importaciones, favoreciendo la integración al mercado global. En el ámbito político, al finalizar el siglo pasado, el Partido Revolucionario Institucional (PRI), dominante durante 70 años, había sido desplazado por la oposición, no sólo en el gobierno federal, también en una gran cantidad de estados y municipios, abriendo así la posibilidad de la alternancia política. Esta situación se presenta como resultado de un proceso complejo en el que se mezclan las luchas y reivindicaciones de la sociedad civil, las disputas de las fuerzas políticas por el poder y las fuertes influencias externas de exigencia de democratización como requisito para la participación comercial internacional (Aguilar, 2005; Camp, 2006; Levy \& Bruhn, 2006).

Este contexto de alternancia política y de participación en la globalización económica ha tenido un impacto en las condiciones de generación de la comunicación pública en México, la cual parece estarse modificando según ciertas tendencias:

- A finales de la década de 1990, los medios parecían adaptarse al modelo liberal capitalista, situación que los distanció de los contenidos oficiales (Demers, 2002; Hallin, 2000a; Hernández, 2004; Trejo, 1995-1996).

- La información política ha quedado descentrada y aparecen hibridaciones como la articulación de periodismo, entretenimiento y publicidad (Hallin, 2000b; Hernández, 2000; Orozco \& Medina, 2000).

- Se han diversificado los grupos de la sociedad civil organizada que intervienen en el espacio mediático y se han ampliado las rutas de acceso al espacio público para los ciudadanos comunes (Alva, 2007; Escobedo, 2003; Ramírez, 2008). 
Este documento ofrece una aproximación a una investigación amplia ${ }^{2}$ cuya pregunta principal plantea: ¿cómo se manifiestan los cambios provocados por el proceso de democratización y apertura comercial en la configuración ${ }^{3}$ de la comunicación pública en México? El ámbito de la comunicación pública representa un espacio de participación constituido por actores políticos, corporativos y civiles que actúan dentro de sistemas de información, tanto institucionales como informales. Así mismo incluye prácticas comunicativas orientadas a la discusión de los temas de interés público como la comunicación política, la comunicación mediática, la publicidad, la comunicación en redes y las relaciones públicas (Beauchamp, 1991; Demers, 2008; Lavigne, 2008).

El objetivo del estudio consistió en reconocer la manera en la que se ha configurado la comunicación pública en México mediante un análisis empírico y situado, a partir de los cambios identificados en las dimensiones económica, política y sociocultural, considerando un conjunto de determinaciones que establecen un sistema relacional en el que el ámbito de la comunicación pública resulta afectado (véase Tabla 1).

Se plantea un proceso de cambio en la comunicación pública a partir del contraste de las condiciones políticas y económicas de México, tomando como referencia la segunda mitad del siglo XX y el periodo finisecular. El supuesto es que la configuración de la comunicación pública cambia porque las condiciones políticas y económicas se han transformado. El cambio se presenta como una adaptación a esas nue-

2 La investigación completa puede ser revisada en la siguiente dirección electrónica: $\mathrm{http}$ ://ccdoc.iteso.mx/acervo/cat.aspx?cmn=browse \&id=5454

3 Configuración social es una noción teórica propuesta por Norbert Elias (1993), se trata de "la figura global y siempre cambiante que forman los participantes de un conjunto de relaciones recíprocas" (p. 156). Esta noción busca eliminar la ilusión de dos esferas distintas (individuo y sociedad), pues lo que existe es un proceso de interacción entre los actores y su entorno, reconoce un conjunto de relaciones entre los individuos que participan en la configuración y está constituida por esferas envolventes en donde una configuración siempre forma parte de otra más amplia en la que interactúa, transforma y es transformada por otros. Ofrece una perspectiva compleja, dinámica y relacional de sociedad. 
TABLA 1

AFECTACIONES INTERRELACIONADAS QUE CONTRIBUYEN

A LA CONFIGURACIÓN DE LA COMUNICACIÓN PÚBLICA

EN EL MÉXICO CONTEMPORÁNEO

\begin{tabular}{|c|c|c|c|}
\hline & & \multicolumn{2}{|c|}{ Manifestaciones } \\
\hline & & $\begin{array}{c}\text { Segunda mitad } \\
\text { del siglo XX }\end{array}$ & $\begin{array}{c}\text { Periodo finisecular } \\
(\text { siglos XX-XXI })\end{array}$ \\
\hline \multirow{3}{*}{ 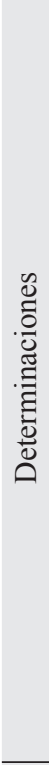 } & Económica & $\begin{array}{l}\text { Economía cerrada en el } \\
\text { espacio nacional caracte- } \\
\text { rizada principalmente por } \\
\text { el modelo de industria- } \\
\text { lización y sustitución de } \\
\text { importaciones }\end{array}$ & $\begin{array}{l}\text { Economía abierta de par- } \\
\text { ticipación en el mercado } \\
\text { global }\end{array}$ \\
\hline & Política & $\begin{array}{l}\text { Permanencia de un parti- } \\
\text { do único en el gobierno en } \\
\text { todos sus niveles }\end{array}$ & $\begin{array}{l}\text { Inicio de un proceso de } \\
\text { alternancia política en } \\
\text { el que distintas fuerzas } \\
\text { gobiernan los diferentes } \\
\text { niveles }\end{array}$ \\
\hline & Sociocultural & $\begin{array}{l}\text { Espacio público cerrado } \\
\text { caracterizado por la ten- } \\
\text { dencia a la representación } \\
\text { oficial del acontecer }\end{array}$ & $\begin{array}{l}\text { Espacio público más } \\
\text { abierto, descentramiento } \\
\text { de la política y de los ac- } \\
\text { tores públicos; por ende, } \\
\text { de la representación del } \\
\text { acontecer }\end{array}$ \\
\hline 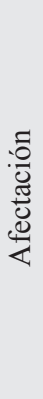 & $\begin{array}{l}\text { Comunicación } \\
\text { pública }\end{array}$ & $\begin{array}{l}\text { Medios de comunicación } \\
\text { y sistemas de información } \\
\text { subordinados al gobierno } \\
\text { a través de mecanismos } \\
\text { de dominación para el } \\
\text { control de la información } \\
\text { (Bohmann, 1994; Ca- } \\
\text { rreño, 2000; Fernández, } \\
\text { 1993) }\end{array}$ & $\begin{array}{l}\text { Medios de comunica- } \\
\text { ción y sistemas de in- } \\
\text { formación más libres; } \\
\text { simultánea y paradóji- } \\
\text { camente se sofistican los } \\
\text { mecanismos de control } \\
\text { de la información (Ha- } \\
\text { llin, 2000a; Hernández, } \\
\text { 2004; Trejo, 1995-1996) }\end{array}$ \\
\hline
\end{tabular}


vas condiciones por parte de los actores correspondientes, quienes operan por lo menos desde dos tendencias: minimizando y controlando las transformaciones para evitar perder el poder, o estimulándolas para tratar de empoderarse.

\section{DELIMITACIÓN DEL ESTUDIO}

\section{Y ASPECTOS TEÓRICO-METODOLÓGICOS}

Esta investigación está desarrollada desde una perspectiva de región, recuperando experiencias situadas en la ciudad mexicana de Aguascalientes. Las prácticas de la comunicación pública locales, junto con las condiciones que organizan la vida política y económica de México, e integradas a las tendencias globales, exigen un eje de reflexión sobre la comunicación pública contemporánea. El escenario local ofrece un contexto de ocurrencia para hibridar lo propio y lo externo, desde donde se reinventa lo público y las formas de participar públicamente.

La comunicación pública como propuesta teórica es amplia (véanse Demers, 2008; Demers \& Lavigne, 2007; Martín-Serrano, 1994; Thompson, 2003, entre otros). En este estudio se toma al periodismo político como punto analítico de entrada porque consiste en un proceso social en el cual converge la producción y distribución de la información contemporánea, los canales tecnológicos de difusión y el ejercicio del poder que los orienta.

Por periodismo político se entiende las prácticas desarrolladas para informar sobre la esfera en la que se relacionan actores como los medios noticiosos, el Estado, las instituciones (públicas y/o privadas) y los grupos de interés o espontáneos de la sociedad civil, entre otros, contribuyendo a la constitución de una agenda de discusión denominada asuntos de interés público (Demers \& Lavigne, 2007).

El periodismo es una actividad compleja de producción informativa en la que intervienen sujetos e instituciones en una articulación múltiple que condensa el control social y la institucionalización de prácticas (Hirsch, 1980), conectando diversos niveles de actividad en las dimensiones política, económica y simbólica (Sánchez Ruiz, 1992).

Las prácticas contemporáneas del periodismo se insertan en una tendencia global hacia la uniformidad. Según Hallin y Mancini (2004) 
este proceso pasa por la homogenización que disemina los valores periodísticos estadounidenses por ser la visión dominante en el mundo, agrupados en un modelo al que denominan liberal, el cual se reconoce, grosso modo, por el incremento de los medios comerciales (empresas privadas), la separación entre noticias y opiniones como un valor fundamental del periodismo, su diferenciación respecto del sistema político, el uso de la mercadotecnia política y la idea de que la globalización y la democracia se relacionan con el capitalismo.

Estos principios combinados con otros procesos -por ejemplo, el desarrollo tecnológico- ofrecen las condiciones para que se presenten fenómenos como las hibridaciones, la convergencia, la fragmentación de las audiencias y el uso de la tecnología de comunicaciones, mismos que intervienen para que se generen cambios importantes en el espacio público-mediático y, consecuentemente, en el periodismo.

Debido a que la finalidad del estudio es la reconstrucción analítica de procesos sociales complejos se optó por una aproximación cualitativa en la que se desarrolló una estrategia de etnografía multisituada (Marcus, 1995). Las instancias de comunicación institucional del gobierno, de los partidos políticos y de otras organizaciones funcionaron como escenarios clave desde donde dirigir el proceso de observación. La información se complementó con entrevistas practicadas a cuatro tipos de actores: periodistas, empresarios de los medios, políticos y comunicadores institucionales.

El periodo de la observación abarcó de enero de 2007 a diciembre de 2008. Durante ese tiempo se realizaron también las entrevistas hasta llegar a un total de 20. El número de entrevistas estuvo determinado por el principio de suficiencia comparativa, cuando los datos otorgados alcanzaron el nivel de saturación.

La información fue interpretada bajo los principios de una hermeneútica profunda (Thompson, 1998) o doble (Giddens, 2006), lo que implica que el saber sociológico se basa en la interpretación que el analista formula sobre la que previamente ofrecen los sujetos. Se formaron cuatro ejes progresivos de organización de los datos: a) relaciones entre periodismo y poder político, b) procesos de cambio en la comunicación pública, c) estrategias de resistencia a los cambios, d) estrategias para estimular cambios. 


\section{EL CONTEXTO DE INVESTIGACIÓN}

México constituye el contexto amplio de referencia para el objeto de investigación, mientras que Aguascalientes representa el recorte empírico de observación. En lo económico, el dato importante es el actual modelo de apertura comercial al extranjero para incorporarse a la globalización. En el aspecto político hay que destacar las transformaciones del sistema político mexicano motivado por sus propios excesos y por las exigencias de la sociedad civil. Estas transformaciones llevaron al término del régimen del PRI al concluir el siglo XX, lo que ha permitido el relevo de los partidos políticos en los niveles federal, estatal y municipal, así como en la conformación de las asambleas parlamentarias. Esta situación constituye un avance en la transición a la democracia, aunque existen autores que denuncian su fragilidad (Villafuerte, 2005).

Respecto de la comunicación pública, encontramos que los medios y el periodismo tuvieron un comportamiento subordinado al gobierno durante la mayor parte del siglo XX. A través del gasto gubernamental y otros mecanismos, el gobierno controlaba eficazmente la representación mediática de sí mismo (Bohmann, 1994; Carreño, 2000; Fernández, 1993).

De manera coincidente con el cambio político y la apertura económica al extranjero aparecieron medios independientes y comercialmente sólidos. Esto ha modificado la relación de los medios con los gobernantes. Ahora se mostraba un tratamiento más crítico de la información como tendencia general (Hallin, 2000b; Hernández, 2004; Trejo, 1995-96). Así mismo, hubo modificaciones en algunas legislaciones relacionadas con aspectos de la comunicación pública, como lo muestran Gutiérrez (2005) y Ramírez (2008).

Desde lo local, Aguascalientes ha tenido un cambio acelerado a partir de la década de 1980, cuando su economía giró de agropecuaria a industrial. En la actualidad, la entidad aparece como un emplazamiento de negocios exitoso y el gobierno local se ha preocupado por diseñar políticas de atracción a la inversión (Ortega, 2005).

En lo político, Aguascalientes vivió la alternancia desde las elecciones municipales de 1995 y estatales de 1998 al triunfar el Partido 
Acción Nacional (PAN). En las últimas elecciones municipales (2007) y estatales (2010), el PRI ha recuperado el gobierno. De la misma manera, se observa poca cohesión de la sociedad civil organizada que demande y reivindique sus derechos.

Respecto de la comunicación pública, el desarrollo de los medios de comunicación ha sido tardío: la radiodifusión inició hasta 1936, la prensa moderna se consolidó hasta la mitad del siglo XX y la televisión local apareció en la década de 1970, pero se fortaleció hasta 1990. Las actividades desarrolladas por las unidades de relaciones públicas y prensa de las instancias gubernamentales han sido importantes en la mediatización de la información política. También pueden observarse adecuaciones en la normatividad relacionada con la comunicación como la formulación de la ley estatal de acceso a la información pública y la derogación de los "delitos contra el honor" del código penal que ponían limitantes al trabajo periodístico (véase Tabla 2).

\section{CAMBIOS EN LA CONFIGURACIÓN}

DE LA COMUNICACIÓN PÚBLICA EN AGUASCALIENTES

El sexenio de 1992-1998 fue el último en el que el PRI gobernó el estado de Aguascalientes. En ese periodo el principal rasgo de las relaciones entre periodismo y gobierno consistía en una doble estrategia de control: la movilidad social de los periodistas y los mecanismos de control en los niveles personal e institucional.

Eran ferrocarrileros muchos de ellos porque era la profesión de este estado, y muchos eran de otras profesiones totalmente diferentes a ser periodistas, a realmente haber aprendido el oficio en las aulas; y que un día les dijeron: "oye, ¿por qué no escribes de béisbol?, a ti que te gusta tanto asistir a los partidos", y "¿por qué de béisbol no te vienes a las locales?, ya que tienes un amigo que es del sindicato y cubres la fuente de sindicatos", y fue así como empezaron (Entrevista con comunicadora institucional del gobierno, 24 de marzo, 2007).

La movilidad social se manifestaba como la capacidad de escalar el éxito laboral por la cobertura de las fuentes informativas que permitía a los periodistas tener roce e influencia con la élite política. A ello se 
TABLA 2

MEDIOS DE COMUNICACIÓN EN AGUASCALIENTES, 2010

\begin{tabular}{|c|c|c|}
\hline \multicolumn{2}{|c|}{ Tipo de medio } & Nombre del medio \\
\hline \multirow{10}{*}{\multicolumn{2}{|c|}{ Impresos }} & El Sol del Centro \\
\hline & & El Heraldo de Aguascalientes \\
\hline & & Hidrocálido \\
\hline & & Página 24 \\
\hline & & Aguas \\
\hline & & La Jornada Aguascalientes \\
\hline & & Tribuna Libre (semanario de nota roja) \\
\hline & & Semanario Político-Policíaco \\
\hline & & (semanario de nota roja) \\
\hline & & $\begin{array}{l}\text { Periódico político-policíaco El Circo } \\
\text { (de nota roja) }\end{array}$ \\
\hline \multirow{9}{*}{\multicolumn{2}{|c|}{ Radio }} & Radio Grupo (6 concesiones: 4 en AM \\
\hline & & y 2 en FM) \\
\hline & & Radio Universal ( 7 concesiones: 5 en AM \\
\hline & & y 2 en FM) \\
\hline & & Grupo Radiofónico Zer (2 concesiones: 1 en \\
\hline & & AM y 1 en FM) \\
\hline & & Radio Universidad (1 permiso en FM) \\
\hline & & Radio Estatal ( 2 permisos: 1 en AM y 1 en FM) \\
\hline & & Stereo Mendel (1 permiso en FM) \\
\hline \multirow[t]{7}{*}{ Televisión } & \multirow[t]{3}{*}{$\begin{array}{l}\text { Señal } \\
\text { abierta }\end{array}$} & $\begin{array}{l}\text { Aguascalientes TV (permiso, televisión } \\
\text { estatal) }\end{array}$ \\
\hline & & Televisa Aguascalientes (concesión, un canal) \\
\hline & & $\begin{array}{l}\text { TV Azteca Aguascalientes (concesión, } \\
\text { un canal) }\end{array}$ \\
\hline & \multirow[t]{4}{*}{$\begin{array}{l}\text { Señal } \\
\text { restringida }\end{array}$} & $\begin{array}{l}\text { Cable Canal (un canal local en sistema } \\
\text { de cable) }\end{array}$ \\
\hline & & Gigacable (un canal local en sistema de cable) \\
\hline & & CV+ TV (un canal local en sistema de cable) \\
\hline & & $\begin{array}{l}\text { Ultravisión (un canal local en sistema de TV } \\
\text { con señal de microondas) }\end{array}$ \\
\hline
\end{tabular}


agregaba la recompensa económica mediante comisiones por venta de publicidad y por sobornos. Esta acción elevaba sus ingresos en contraste con sus precarios salarios designados.

Quincenalmente a cada uno le mandaban su cheque. Los reporteros que cubrían la fuente, los directores de los medios, a todos les tocaba. Los más descarados siempre han sido los fotógrafos. Ellos cada quincena iban y hacían cola, a recibir su sobre como ellos le llamaban. "Venimos por nuestro sobre" o "venimos por nuestro chayo"... (Entrevista a comunicadora institucional del gobierno, 3 de marzo de 2007).

La compra de espacios publicitarios para la difusión de información oficial constituía el principal financiamiento de las empresas periodísticas, en concordancia con el esquema establecido en todo el país (Bohmann, 1994; Carreño, 2000; Fernández, 1993). A esto se sumaban estrategias de control de contenidos, como la elaboración de boletines oficiales. Los boletines presentan a los periodistas la orientación interpretativa de los actos gubernamentales bajo la apariencia de provisión inocua de información.

Por ejemplo, yo sabía que pues... que era el área de información, y que hacían boletines, y que luego esos boletines los publicaban en el periódico, y nosotros los recortábamos y los pegábamos (Entrevista a comunicadora institucional del gobierno, 3 de marzo de 2007).

Se establecía una simulación por medio de la cual se pretendía impactar a la opinión pública echando a andar un mecanismo de difusión oficial. Así, los medios de comunicación locales asumían el papel del difusores gubernamentales, mientras el gobierno los monitoreaba $-\mathrm{y}$ aún lo hace- sistemáticamente.

Con la llegada del PAN al gobierno del estado en 1998, el esquema anterior se modificó, disminuyendo considerablemente la participación económica del gobierno en los medios locales. El proceso fue abrupto y radical. Una de las primeras consecuencias resultó en un conflicto entre la élite gobernante y el sector mediático, lo cual para los medios periodísticos locales significó una doble transformación: se 
encontraron repentinamente desamparados del gasto gubernamental, pero también independientes del poder político. Contrario a la costumbre, tomaron una postura de confrontación generando información con orientación crítica.

Llega Felipe González [al gobierno del estado, 1998-2004] y de sus primeras acciones es: "desaparece el área de prensa... nada para nadie... de ahora en adelante no va a haber un peso para nadie". Entonces imagínate, o sea, era un vicio tan arraigado, que como intención era buena, pero yo le veía un gran riesgo, porque era un vicio tan arraigado que requería un proceso para erradicarse (Entrevista a comunicadora institucional del gobierno, 3 de marzo de 2007).

Lo anterior tiene al menos dos lecturas, una política y la otra económica. Respecto de la política, la decisión del nuevo gobierno de disminuir el gasto de difusión aceleró el proceso de distanciamiento con el sector mediático. La medida generó resistencia pero también un nuevo marco para las relaciones entre el poder político y los actores mediáticos. En lo económico, pudo observarse la aparición del riesgo de fracaso de los medios locales como proyecto empresarial. La medida puso a los medios de cara a la lógica del mercado comercial, fuera del paternalismo gubernamental que funcionaba, también, como mecanismo de control.

En ambos casos se mostró un debilitamiento relativo del poder gubernamental y del poder mediático simultáneamente. El poder gubernamental perdió su control total sobre la representación periodística, al tiempo que el poder mediático evidenció su fragilidad como sector empresarial autónomo. La salida del problema fue la negociación estratégica expresada en la celebración de convenios de publicidad gubernamental, como una manera de restablecer las relaciones. Los convenios consisten en el pago adelantado por un año completo de publicaciones en los medios noticiosos.

Entonces es tanta ya la presión sobre Felipe González [gobernador], de la prensa, que explota, o sea, se da cuenta de que ya no puede contra la prensa. Al menos no con sus armas, que él decía tener para controlarla. Entonces se 
da cuenta de la necesidad de soltar billete. Entonces crean una figura por ahí de un convenio con los medios. Como eran rollos [asuntos] administrativos y rollos muy confidenciales, yo nunca entendí muy bien cómo estaba el asunto, pero por lo poco que llegué a comprender, llegaban a convenios, por ejemplo, con los periódicos, un convenio por 20 millones de pesos, para todo el año. Esos 20 millones de pesos, incluyen tantas notas de ocho columnas, tantas fotografías a color, tantas notas en interiores, desplegados, cintillos, todo eso contemplaba (Entrevista a comunicadora institucional del gobierno, 3 de marzo de 2007).

La negociación representa nuevas reglas para la relación entre medios y actores políticos. El cambio de reglas implica una modificación de la operación financiera de los medios de comunicación: de la subvención estatal a la participación en el mercado. Aunque la fuente de financiamiento no cambió, sí lo hicieron las lógicas de inversión en la difusión, así como su significado.

Los convenios de publicidad modificaron la dirección del flujo del poder, el significado de la comercialización del espacio periodístico y las relaciones entre los actores. Dicha dinámica puede ser vista en tres dimensiones: a) la mercantilización del espacio periodístico se ha conformado como la manera central de la participación política a través de los medios, b) los convenios de publicidad aparecen como nuevos instrumentos de control de las representaciones periodísticas, c) se evidencia la emergencia de nuevos actores que amplían el espacio público-mediático local.

Un rasgo de los convenios es que se realizan de manera secreta, o por lo menos oculta de la visibilidad pública. En esta investigación ha sido posible acceder a su conocimiento por la vía testimonial, pero no de manera documental. En consecuencia, se desconocen los montos exactos de las inversiones correspondientes.

Sin embargo, es posible acercarse a las cantidades que el gobierno estatal destina para estos convenios mediante la revisión del informe del gasto público, específicamente en el rubro de "Servicios de difusión e información", publicado por la Secretaría de Finanzas (Gobierno del Estado de Aguascalientes, 2005, 2010) (véase Tabla 3). 


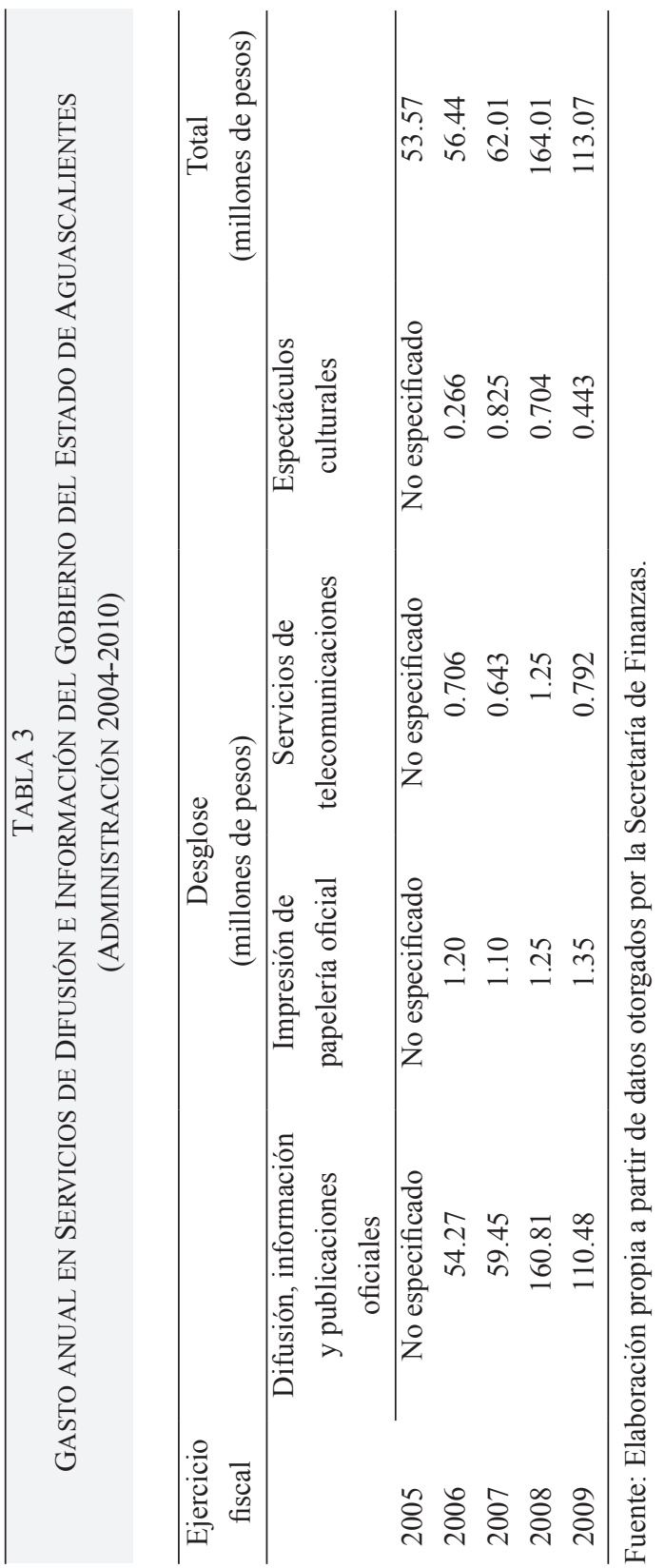


Puede observarse que la cuenta "Difusión, información y publicaciones oficiales" concentra la mayor cantidad de la inversión y presenta incrementos paulatinos, por encima de los 50 millones de pesos, hasta el año 2008, cuando el gasto ejercido aumenta de modo abrupto, casi el triple, y un descenso de 50 millones en 2009.

Desde la lógica empresarial, la celebración de los acuerdos aparece como una relación mercantil legítima que permite el cobro por la prestación de un servicio. Este ambiente de mercantilización permite la construcción de un discurso supuestamente ético con tres premisas: a) los medios de comunicación son empresas privadas con derecho a capitalizar su actividad, b) la facturación otorga legitimidad a esa capitalización al desaparecer la discrecionalidad y c) el periodista deja de ser agente de ventas y por lo tanto deja de percibir beneficios que lo comprometen con las fuentes informativas.

A pesar de este discurso, en la práctica se puede observar una influencia de la publicidad sobre el periodismo, pues los convenios en este sentido determinan el tratamiento favorable dado a la información, aún la no convenida, por lo que no quedan claros los límites de los alcances de los convenios de publicidad en la cobertura periodística. Las siguientes referencias empíricas muestran esa ambivalencia.

Pero en eso se han convertido los medios de comunicación: en un juego de intereses... Esa relación, es una relación muy compleja, la relación con el poder y la relación con la sociedad. Es una relación... yo al menos te puedo decir en el caso de nuestros medios, buscamos hacer un periodismo en el que estamos separados por completo de gobierno, es decir, yo tengo una relación de negocios con gobierno, pero esa relación no invade mi oficina de periodismo (Entrevista con empresario radiofónico, 25 de septiembre, 2007)

La llevo bien por dos, y lo digo claramente, por dos cuestiones: una es por el acuerdo de publicidad, pero aún con el acuerdo de publicidad podría llevármela mal, pero también existe la relación de no solamente ver a un medio, o un propietario, o un reportero, o director como parte de interés mutuo de publicidad y de ingreso al medio, sino también de amistad, de una buena relación fuera de la comercial, fuera del interés personal como gobierno y 
como empresario, y bajo ese concepto el del contrato de publicidad, más el de buena relación personal, nos hemos llevado muy bien (Entrevista con presidente municipal, 21 de septiembre, 2007).

El contenido publicitario resultante de los convenios transforma las "gacetillas"4 en publirreportajes, en tanto que constituyen un híbrido de contenido noticioso pero con fines promocionales. Aunque su distinción respecto de las noticias normales pudiera quedar clara para los actores, siempre queda pendiente el análisis de su presentación a los públicos. La presentación de los publirreportajes como si se tratara de noticias verídicas, alude a la discusión entre la veracidad del periodismo y la falsedad y exageración de la publicidad (Gauthier, 1992), muestra la hibridación entre los dos y, en un escenario más amplio, revela las inconsistencias y contradicciones de la transición democrática mexicana, en la cual los sistemas para nutrir de información a la sociedad carecen de confiabilidad por el alto nivel de control de parte de las élites.

Resulta que el gobierno del estado está vendiendo kilos de tortilla a 6.50 pesos. Es un paquetote... entonces el compromiso de Luis Armando [gobernador, 2004-2010] fue vender 20 toneladas de tortilla cada tercer día, lunes, miércoles y viernes, en todo el estado. Entonces, pues sí, dijimos: "nos aventamos el tiro". En 400 puntos de venta. Entonces resulta que el día del arranque del programa fue un show porque el proveedor llegó con 2 toneladas de tortillas en vez de 20, de los 400 puntos que eran, nada más había 16... Bueno, entonces me dicen: "hay que hacer un boletín". Ok, yo hago un boletín. El encabezado de mi boletín decía: "Con gran éxito arrancó el programa de venta de tortilla a bajo costo. Tan sólo en el primer día se distribuyeron 20 toneladas de tortillas en todo el estado en 400 puntos de venta". O sea, no era verdad (Entrevista con comunicadora institucional del gobierno, 3 de marzo, 2007).

4 Término de la jerga periodística para designar los boletines informativos oficiales publicados mediante pago, en el contexto de las relaciones entre medios y gobierno durante la segunda mitad del siglo XX. 


\section{LAS APERTURAS DEL ESPACIO PÚBLICO-MEDIÁTICO}

No obstante las estrategias de las élites políticas para contener los cambios, el propio proceso de la transición política y económica del país ha generado, a su vez, aperturas en el espacio público-mediático inherentes a un nuevo estado de las cosas. En este trabajo, esas aperturas han sido identificadas así:

- Modificaciones en los liderazgos políticos.

- El ideal periodístico.

- Los actores de la sociedad civil.

- La emergencia de la delincuencia organizada.

- Tensiones entre lo local-nacional-global.

\section{Modificaciones en los liderazgos políticos}

Los cambios en México han implicado también el debilitamiento del presidencialismo y los cacicazgos locales. El fortalecimiento de la competencia política ha hecho emerger a los grupos internos de los partidos que establecen una contienda permanente por ganar posiciones de poder.

Para ilustrar estas transformaciones referiré a un proceso registrado en el diario de campo5: la bursatilización del Impuesto Sobre la Nómina (ISN). Este proceso evidencia la pérdida de poder del mandatario local sobre su partido, la percepción de los actores políticos respecto del tratamiento periodístico de sus figuras, así como la zona estratégica de acción concedida a los comunicadores institucionales para el posicionamiento noticioso de los liderazgos políticos.

El 27 de diciembre de 2006, el legislativo local autorizó al gobierno del estado, de extracción panista, un endeudamiento público por 2,000 millones de pesos, usando como garantía el ISN de reciente creación. Sin embargo la dirigencia estatal del propio PAN se opuso a ello y desarrolló una serie de acciones para evitar la deuda, que incluía un despliegue mediático para generar presión.

Aparecieron dos polos de poder. La autoridad del mandatario local se mostró fracturada. El enfrentamiento entre la dirigencia del PAN y

5 La escritura del diario de campo corresponde al periodo de observación participante, de enero de 2007 a diciembre de 2008. 
el gobierno del estado por la bursatilización tomó como escenario el espacio mediático y se convirtió en una lucha por la legitimidad pública. El instrumento del conflicto fueron las ruedas de prensa. Conforme fue avanzando el año 2007, el enfrentamiento fue estableciéndose como una estructura de producción y de lectura de las noticias, misma que se actualizaba conforme aparecían nuevos temas en la agenda periodística. Paralelamente se iban integrando otros actores en el conflicto a favor de uno u otro bando: empresarios, líderes sindicales, representantes de otros partidos políticos, líderes eclesiásticos.

En el proceso también fue posible observar diferentes estilos en el manejo de las relaciones públicas. Por un lado, los comunicadores institucionales del PAN mostraron una actitud de bajo perfil. El estilo del gobierno del estado fue osado y protagónico.

Siempre tienes que ser sigiloso en materia de medios, siempre tienes que ser sigiloso, es un principio, cuando tú sales a los medios, cuando no tienes algo pensado, las repercusiones que puede tener ... no te va a ir bien (Diálogo con comunicador institucional de partido político, 5 de enero, 2007).

Es parte también de los procesos que se viven en las áreas de comunicación, en donde el comunicador ya no se queda detrás del candidato, detrás de la bocina para grabar el audio, sino que también posiciona y apoya en las labores de difusión del gobierno (Entrevista con comunicadora institucional del gobierno, 24 de marzo, 2007).

\section{El ideal periodístico}

Conforme se desarrollaba el trabajo de campo, los actores manifestaban un referente compartido respecto de la manera ideal de ejercer el periodismo: el esquema de trabajo del grupo Reforma a través de su corresponsal en el estado. En el contexto de Aguascalientes, las condiciones económicas de una empresa periodística nacional como Reforma, con un proyecto editorial innovador en términos de la regularidad del periodismo mexicano durante todo el siglo XX (como lo hace notar Trejo, 1995-1996), contrastan con la realidad cotidiana de los medios locales.

Sobresale la mención de tres aspectos: a) la recepción de un buen sueldo, b) la práctica del periodismo de investigación y c) la negación, 
por normatividad, para aceptar festejos, reconocimientos y favores de las fuentes informativas como una manera ritualizada de garantizar autonomía editorial. Lo anterior aunado a la poca capacidad de influencia de intervención por parte del gobierno local sobre la dirección del medio. La presencia del corresponsal de Reforma constituye la constatación de la tendencia -o quizá la simple aspiración- hacia el modelo liberal de periodismo.

Existen otros casos de tipo local que también aluden al periodismo ideal, como el desaparecido programa radiofónico "Comentando la Noticia" en la estación XEBI del corporativo local Radio Grupo. Funcionaba como panel en donde participaban las principales figuras políticas para discutir los temas principales nacionales y locales. La visión crítica del programa motivó la censura de ese espacio, al parecer por órdenes gubernamentales, según la recomendación número 016/2008 de la Comisión Nacional de Derechos Humanos (CNDH, 2008), que acredita "violaciones a la libertad de expresión e información, información, así como a la legalidad, seguridad jurídica y al honor".

Estos dos casos muestran las aperturas del espacio periodístico local a pesar de los controles establecidos por las élites. En el segundo caso, llama la atención la presencia de instancias institucionales, como la $\mathrm{CNDH}$, con disposición y función de emitir recomendaciones a gobernantes para evidenciar el abuso de poder. Se revela en ello una modificación estructural del sistema político mexicano, derivada de los procesos de democratización, para reconocer y denunciar el autoritarismo; aunque no se pueda garantizar todavía su eficacia.

\section{Los actores de la sociedad civil}

Los políticos y los comunicadores institucionales establecen una vigilancia de las fronteras de la sala de prensa, pero ante el debilitamiento relativo del poder político, ocurre la presencia de actores que participan en otro tipo de esferas y que parecen mantenerse sujetas a los criterios de selección y jerarquización del material noticioso fuera de la influencia financiera del gobierno.

Son actores alternos que luchan por el acceso a los medios noticiosos mediante estrategias diversas y con resultados también diversos. La Liga de la Leche Internacional es una organización de madres de 
familia que promueven la lactancia materna mediante la constitución de grupos de apoyo que funcionan como una red global con reuniones locales. Durante la celebración de la Semana Internacional de Lactancia Materna (del 1 al 7 de agosto de 2008) convocada por la Alianza Mundial pro Lactancia Materna6 (WABA, por sus siglas en inglés), las líderes de la Liga de la Leche en Aguascalientes se acercaron a la Comisión de Salud del Congreso del Estado y negociaron con los diputados una convocatoria conjunta a una rueda de prensa.

En términos de publicación de la información, los resultados fueron diversos. Algunos medios la difundieron y otros la ignoraron. Esto demuestra que los criterios de selección noticiosa con los que operan los productores de información periodística no son homogéneos cuando no proceden por la lógica mercantil. La estrategia de convocar a los reporteros por la vía de la negociación con una instancia legitimada como fuente informativa -el Congreso del Estado- sirve para recibir cobertura, pero no garantiza la publicación de la información si la misma no está apoyada. 7

En otras ocasiones es posible aprovechar los espacios que eventualmente se abren para insertarse en el espacio público-mediático. La celebración del natalicio de Benito Juárez, el 21 de marzo de 2007, permitió compartir la tribuna pública a tres actores habitualmente disociados: el gobierno del estado, la sociedad masónica y los Testigos de Jehová. Las dos últimas asociaciones representan alteridades que normalmente no son asumidas por el gobierno como interlocutores en los relatos noticiosos.

Existen actores sociales insertos en la dinámica de la subpolítica, ${ }^{8}$ desarrollando estrategias para lograr el acceso a los medios noticiosos. En los casos observados, se gestionó la visibilidad pública negociando una presencia compartida que ofrece a los actores dominantes la posibilidad de acumular capital político y a los alternos la colocación mediática, aunque sólo sea coyuntural.

6 World Alliance for Breastfeeding Action.

7 Término que en la jerga periodística se refiere al pago por publicación.

8 De acuerdo con Beck (1997), la subpolítica consiste en la conformación de redes formales e informales para satisfacer necesidades que las instituciones no son capaces de solucionar por su rigidez. 


\section{Delincuencia organizada y violencia extrema}

A partir de los últimos meses del año 2006, en Aguascalientes se han verificado hechos de violencia extrema sin precedentes, vinculados con actividades de la delincuencia organizada tales como ejecuciones de policías, militares y civiles, persecuciones, secuestros, tiroteos, entre otras cosas. Tales acontecimientos han constituido relatos noticiosos tipo what-a-story (Berkowitz, 1992), es decir, historias que por circunstancias particulares del contexto en el que se presentan revisten especial espectacularidad.

Con la violencia exacerbada en la ciudad, emergió de manera repentina la visibilidad mediática de grupos delictivos antes asociados con regiones distantes del país, y por lo tanto desvinculados de la realidad noticiosa local, como el grupo de los Zetas (brazo armado del cártel de la droga de Ciudad Juárez) y las diferentes bandas de narcotraficantes y secuestradores que operan en el territorio nacional.

La emergencia de la violencia movilizó la atención de los medios periodísticos hacia otros emplazamientos con la finalidad de comprender mejor el acontecer local a partir de las experiencias de violencia extrema en otras ciudades de México o del extranjero. Las comparaciones se hicieron inevitables. Se abrió un espacio de periodismo translocal (Martini, 2005) debido a que noticias de este tipo ya no pueden ser identificadas como locales o nacionales, sino que forman parte de problemáticas que trascienden los territorios, fenómenos globalizados.

Otro punto importantísimo es la seguridad pública, o sea se ha magnificado esto a tal grado que ya se dice [en los medios] que Aguascalientes, ya es como un Tijuana, un Ciudad Juárez, cuando sabemos que la realidad es que estamos lejísimos de una ciudad como ésas. Entonces esto, lejos de crearle a la ciudadanía una simple preocupación, pues le crea un estatus de psicosis, ¿qué me va a pasar?, ¿me van a asaltar?, ¿me van a matar?, ¿me van a...?, mil cosas. Que en realidad sabemos que la ciudad de Aguascalientes sigue creciendo día con día a un ritmo muy acelerado y que, obviamente, como todas las ciudades grandes conforme va a creciendo, va presentando diversos problemas que hay que ir atendiendo (Entrevista con funcionario municipal, 9 de enero, 2007). 
Los datos arrojados por el trabajo de campo en este terreno son demasiado limitados, pero la emergencia de esta condición hace notar la necesidad de elaborar investigaciones posteriores que permitan observar la ampliación de la comunicación pública con la integración de actores de confrontación como la delincuencia organizada.

\section{Conexiones de lo local-nacional-global}

A pesar de que las acciones referidas de los grupos de la sociedad civil y de la delincuencia organizada se presentan en el ámbito de las noticias locales, en realidad el espacio de acción de estos grupos rebasa ese nivel y se inserta en dinámicas nacionales y globales. También la propia dinámica de relación entre los actores de la producción periodística se establece a partir de la incorporación de mecanismos estandarizados, como las negociaciones relativas a los convenios de publicidad y las nuevas relaciones que los acompañan. Esta manera de proceder parte de premisas que conforman las tendencias internacionales de la práctica del periodismo y de las relaciones públicas.

Estos procedimientos son resultado de experiencias extranjeras, específicamente de Estados Unidos, que presentan condiciones particulares de participación política a través de lo mediático. La reproducción de esos procedimientos en los contextos nacional y local conduce a actividades estandarizadas para el uso utilitario del espacio periodístico. Esto se integra a un modelo global en el manejo de las relaciones públicas (véanse Davis, 2000; Lavigne, 2005), con poca reflexión de su aplicación en el ámbito local.

El media training en una oficina de comunicación social yo creo que no es un curso al año que vas y que: "ay mira que bonito [tomas] fotografías". No, yo pienso que el media training es diario y es saber qué está diciendo la prensa, sentarte con tu jefe, qué vas a decir, cómo vas a salir en este sentido, y al mismo tiempo convertirte en el principal crítico. Decir: "si sales con esta idea no creo que vaya a beneficiarte en tu imagen, no creo que vayas a estar dando el mensaje que quieres dar, ¿por qué? Porque la prensa actúa así y por lo tanto se puede distorsionar tu mensaje hacia este sentido" (Diálogo con comunicador institucional de partido político, 5 de enero, 2007). 


\section{CONCLUSIÓN}

Las transformaciones de la configuración de la comunicación pública en Aguascalientes, como resultado de la transición política-económica de México se manifiestan principalmente en el uso de una relativa independencia editorial emergente como instrumento de presión para la adquisición de convenios publicitarios, por los que se conduce el flujo de la inversión financiera gubernamental hacia la difusión mediática. A la par, existen espacios -aunque todavía reducidos- para la incorporación de otros actores y temas en el espacio público-mediático.

El periodismo aparece como un espacio de participación en donde los dispositivos mediáticos otorgan la visibilidad necesaria para constituir puntos de referencia respecto de las acciones de otros, quienes también actúan mediáticamente. El acceso al espacio periodístico es resguardado por los actores mediáticos - periodistas y empresarios- y se gestiona por diversas vías que van desde el aprovechamiento de la cobertura periodística hasta la mercantilización. La caracterización del periodismo mexicano en Aguascalientes se presenta como un ejercicio desarrollado en un contexto de poca participación comercial de actores privados, lo que limita la inversión privada publicitaria, retornando la base de su financiamiento al gasto público.

Los mecanismos que obstaculizan la apertura del espacio periodístico podrían mostrar uno de los rasgos de las sociedades en transición: hay una concurrencia de las fuerzas políticas que lleva a los actores gubernamentales a saturar el espacio mediático para promocionarse como parte de los procedimientos de la democracia liberal. Pero esta situación vulnera aspectos más profundos de la democracia, su carácter sustancial, al limitar la diversificación de temas y actores en las noticias y al controlar las fuentes por medio de las cuales los ciudadanos se informan y participan en la deliberación pública.

El acceso al espacio público-mediático se expresa, principalmente, como una mercancía. Ello coloca gran parte de la deliberación pública en el terreno del mercado y constituye un movimiento de privatización de lo público (Bobbio, 2005). A pesar de su expresión novedosa en los convenios de publicidad gubernamental, no constituye en realidad una novedad en la discusión teórica sobre la industria mediática si revisamos las apor- 
taciones de la economía política. Aunque es necesario reconocer que esta tendencia no es totalizante: existen otros actores que no se insertan en la dinámica de la mercantilización del espacio periodístico y generan estrategias funcionales para recibir la cobertura mediática.

El periodismo y el ámbito de lo público-mediático son procesos que se construyen todos los días a partir de prácticas institucionalizadas, por lo tanto, recurrentes e historizadas. Las prácticas que orientan esa construcción son las profesionales, pues el enlace que representan los periodistas y los comunicadores institucionales como poseedores de saberes específicos y actores con una función social determinada es el elemento articulador fundamental de su constitución.

Esto implica que la participación en el ámbito de lo público-mediático exija niveles de especialización. La profesionalización del periodismo constituye un rasgo del modelo liberal de los sistemas mediáticos (Hallin \& Mancini, 2004). Los periodistas y los comunicadores institucionales son mediadores necesarios en la construcción de narraciones del acontecer y en su interpretación con sentido noticioso.

La inversión económica como forma principal de participación en el espacio público-mediático es un criterio dominante de actividad, pues el proceso globalizador enfatiza una ideología vinculada a dos aspectos principales: la democracia como el mejor de los sistemas políticos y el capitalismo como sistema económico ligado a ella. En un efecto de refracción entre los círculos concéntricos que establecen el continuum de lo local-nacional-global, esta ideología se reproduce en los distintos procesos de establecimiento del ámbito de lo público. La profesionalización -y por lo tanto ubicación en el mercado laboral-de las actividades de acceso a los espacios públicos en la forma de las relaciones públicas forman parte de esa lógica. Lo mismo las operaciones mercantiles que orientan la celebración de los convenios de publicidad gubernamental, con la especificidad de la falta de regulación suficiente en México que exacerba su práctica y otorga hegemonía a los actores del gobierno.

La presencia dominante del gobierno en la participación de lo público-mediático, frente a la pobre participación de los actores de la sociedad civil en el caso de Aguascalientes, revela la distinción entre gobernantes y gobernados como un rasgo importante de las relaciones en el espacio público de esta región mexicana. 
Para avanzar en la mejor comprensión de este tema, veo necesario asumir que el periodismo constituye un proceso social complejo que trasciende a los medios de comunicación, aunque tenga ahí su territorio de adscripción. Es necesario entender las relaciones del periodismo con procesos sociales más amplios como los de la construcción de la socialidad, la cultura, la política y la economía en la actualidad.

\section{Bibliografía}

Aguilar, M. (2005). Mouvements sociaux et démocratie au Mexique 1982-1998. Un regard du point de vue régional. Francia: L'Harmattan.

Alva, A. R. (2007). Del recorrido hacia una reforma democrática de los medios: las aportaciones de la "iniciativa ciudadana". En A. Vega, M. Portillo \& J. Repoll (Coords.), Las claves necesarias de una comunicación para la democracia. México: AMIC.

Beauchamp, M. (1991). Communication publique et societé. Repéres pour la réflexion et l'action. Quebec: Gaëtan Morin.

Beck, U. (1997) Modernidad reflexiva. En U. Beck, S. Lash \& A. Giddens, Modernización reflexiva. Política, tradición y estética en el orden social moderno. Madrid: Alianza Universidad.

Berkowitz, D. (1992). Non-routine, news and newswork: Exploring a what-a-story. Journal of Communication, 1 (42).

Bobbio, N. (2005). Estado, gobierno y sociedad. Por una teoría general de la política. México: FCE.

Bohmann, K. (1994). Medios de comunicación y sistemas informativos en México. México: Alianza.

Camp, R. A. (2006). Politics in Mexico. The democratic consolidation. EE.UU.: Oxford University Press.

Carreño, J. (2000, febrero). Cien años de subordinación. Un modelo histórico de la relación entre prensa y poder en México en el siglo XX. Sala de prensa. Recuperado el 11 de marzo de 2008 de www. saladeprensa.org/art102.htm

Comisión Nacional de los Derechos Humanos-CNDH (2008). Recomendación 16/2008. Recuperado el 1 de octubre de 2010 de http// www.cndh.org.mx/estatales/FedMex/documentos/sisnacpred/ SISTEMA/DOCTOS/2008/TESIS\%20RELACIONADAS/32.\%20FLAGRANCIA.\%20SINALOA/16-208.\%20PUEBLA.pdf 
Davis, A. (2000). Public relations, business news and the reproduction of corporate elite power. Journalism. Theory, practice \& criticism, 1(3), 282-304.

Demers, F. (2002). La democratisation du journalisme ou le passage à la gestion d'un droit de parole généralisé: le cas mexicain. Le Cahiers du Journalisme, 10, 248-269.

Demers, F. (2008). La communication publique, un concept pour repositionner le journalisme contemporain. Les cahiers du journalisme, 18, 208-230.

Demers, F. \& Lavigne, A. (2007). La comunicación pública: una prioridad contemporánea de investigación. Comunicación y Sociedad, 8, 65-88. Nueva época.

Elias, N. (1993). Qu'est-ce que la sociologie?. Francia: L'aube.

Escobedo, J. F. (2003). Movilización de opinión pública en México: el caso del grupo Oaxaca y de la Ley Federal de Acceso a la Información. Diálogos, 66, 17-28.

Fernández, F. (1993). Los medios de difusión masiva en México. México: Juan Pablos.

Gauthier, G. (1992). Les enjeux étiques de la communication publique. Cahiers de Recherche Étique, 17, 11-26.

Giddens, A. (2006). La constitución de la sociedad: bases para la teoría de la estructuración. Buenos Aires: Amorrortu.

Gobierno del Estado de Aguascalientes (2005). Egresos por objeto del gasto. Recuperado el 22 de junio de 2009 de http://eservicios. aguascalientes.gob.mx/servicios/sicaf2/Uploads/25-03-2009-0358-10eog_fis05.pdf.

Gobierno del Estado de Aguascalientes (2010). Egresos por objeto del gasto. Recuperado el 21 de mayo de 2010 de http://eservicios. aguascalientes.gob.mx/servicios/sicaf2/Uploads/21-08-2009-0307-27Egresos\%20por\%20objeto\%20del\%20gasto.pdf

Gutiérrez, R. (2005). Información y democracia. Los medios de comunicación social y su influencia sobre la política. El caso de México. México: Ediciones Pomares/UAM-Azcapotzalco.

Hallin, D. (2000a). Media political power, and democratization in Mexico. En J. Curran \& M-J. Park, Dewesternizing media studies. EE.UU.: Routledge. 
Hallin, D. (2000b). La nota roja: periodismo popular y la transición a la democracia en México. América Latina Hoy, 25, 35-43.

Hallin, D. \& Mancini, P. (2004). Comparing media systems. Three models of media and politics. EE.UU.: Cambridge University Press.

Hernández, M.E. (2000). La investigación sobre producción de noticias desde América Latina. En G. Orozco (Coord.), Lo viejo y lo nuevo. Investigar la comunicación en el siglo XXI (pp. 155-168). Madrid: Ediciones de la Torre.

Hernández, M.E. (2004). Del pasado reciente al contexto actual. Mirada sociológica al periodismo mexicano. Revista Mexicana de Comunicación, 89, 31-37.

Hirsch, P. (1980). Occupational, organizational and institutional models in mass media research. Toward and integrated framework. Mass Communication Review Yearbook, 1, 265-294.

Lavigne, A. (2005). L'omniprésence des relationnistes. Des relations de presse stratégiques aux pratiques hors du contrôle des journalistes. En M-F. Bernier, F. Demers, A. Lavigne, Ch. Moumouni, \& T. Watine, Pratiques Novatrices en communication publique (pp. 103-126). Quebec: Les presses de l'Université Laval.

Lavigne, A. (2008). Suggestion d'une modélisation de la communication publique: principales formes discursives et exemples de pratiques. Les Cahiers du Journalisme, 18, 232-245.

Levy, D. \& Bruhn, K. (2006). Mexico. The struggle for democratic development. EE.UU.: University of California Press.

Marcus, G. (1995). Ethnography in/of the world system: The emergent of multi-sited ethnography. Annual Review of Anthropology, 24, 95-117.

Martini, S. (2005). Periodismo, noticia y noticiabilidad. Colombia: Norma.

Martín-Serrano, M. (1994). La producción social de comunicación. México: Alianza Editorial.

Orozco, G. \& Medina, D. (2000). Súper temas noticiosos en la televisión mexicana. Análisis de la información en los noticiarios 24 Horas y Hechos. Comunicación y Sociedad, 37, 53-86.

Ortega, G.F. (2005). Contexto económico del estado de Aguascalientes. Caleidoscopio Revista Semestral de Ciencias Sociales y Humanidades, 18, 157-175. 
Ramírez, J. M. (2008). El acceso a la información pública gubernamental. La gestión de una ley desde las organizaciones cívicas. México: ITESO.

Sánchez Ruiz, E. (1992). Medios de difusión y sociedad. Notas críticas y metodológicas. México: UdeG-CEIC.

Thompson, J. B. (1998). Ideología y cultura moderna. México: UAM.

Thompson, J.B. (2003). Los media y la modernidad. Una teoría de los medios de comunicación. Barcelona: Paidós.

Trejo, R. (1995-1996). Prensa y gobierno: las relaciones perversas. Los medios, espacios y actores de la política en México. Comunicación y Sociedad, 25-26, 35-55.

Villafuerte, L.F. (2005). Las democracias defectuosas y su realidad en México. La palabra y el hombre, 133,137-150. 